\title{
New copper corrosion inhibitors in chloride environments based on $[1,2,4]$ triazolo[1,5-a]pyrimidine-6-carboxylates
}

\author{
A.A. Kruzhilin, ${ }^{1}{ }^{\oplus}$ V.A. Polikarchyuk, ${ }^{1}$ O.A. Kozaderov, ${ }^{1}$

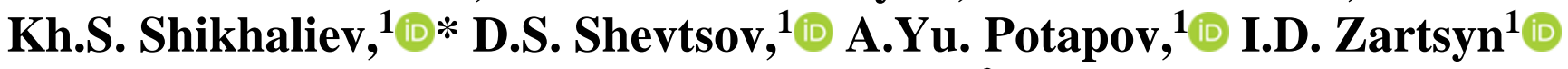 \\ and Ch. Prabkhakar ${ }^{2}$ (D) \\ ${ }^{1}$ Voronezh State University, 1 Universitetskaya pl., 394018 Voronezh, Russian Federation \\ ${ }^{2}$ National Institute of Technology Kurukshetra, Kurukshetra, 136119, India \\ *E-mail: $\underline{\text { shikh1961@yandex.ru }}$
}

\begin{abstract}
The article suggests a new method for the synthesis of new 7-(2-methoxy-2-oxoethyl)$[1,2,4]$ triazolo[1,5- $a]$ pyrimidine-6-carboxylates containing various substituents at position 2 of the triazolopyrimidine matrix, and describes their structure. The inhibitory effect of the synthesised compounds with regard to copper in neutral and acidic chloride environments is evaluated by means of electrochemical and field corrosion tests and quantum chemical calculations. It was found that all the studied compounds inhibit copper corrosion in neutral and acidic chloride solutions. Generally, the degree of protection monotonously grows with an increase in the inhibitor concentration. The results of the tests in an acidic chloride environment mostly correlate with the corresponding results obtained in neutral aqueous electrolyte solutions and are in good agreement with the data of quantum chemical calculations. The greatest inhibitory effect (over 80\%) was observed for 2-mercapto- and 2-amino-derivatives with concentrations of at least $1.00 \mathrm{mM}$. An inhibitory mechanism is explained as a result of the molecules chemisorption on the metal's surface and the formation of self-organizing protective layers due to the presence of endocyclic NH-protons of the pyrimidine cycle in their structures. The suggested mechanism explains the fact that the inhibitory effect of the studied compounds is observed in the dihydropyrimidine tautomeric forms.
\end{abstract}

Received: May 14, 2021. Published: May 31, 2021

doi: $\underline{10.17675 / 2305-6894-2021-10-2-16}$

Keywords: copper, corrosion inhibitors, chlorides, triazole derivatives, triazolopyrimidines.

\section{Introduction}

At the moment, various classes of heterocyclic compounds are widely used as corrosion inhibitors (CI) for non-ferrous metals [1]. Derivatives of aminoazoles are some of the most effective corrosion inhibitors [2]. The most common and the most studied azole-type inhibitors include 1,2,3-benzotriazole together with its substituted analogues and 3aminotriazole derivatives [3]. For rational molecular design and the synthesis of new corrosion inhibitors it is important to take into account the influence of the substituents on the effectiveness of the protection of metals. The ability of the studied metals to form $\sigma$ - and 
$\pi$-bonds in complexes with organic additives usually depends on the side chain. In some cases, the introduction of electron withdrawing substituents to inhibitors facilitates the passivation of the metal, while the introduction of electron donating groups strengthens the $\sigma$-bond of the CI with the metal and enhances its corrosion protection [4]. It is also important to consider the steric effect of the additional substituents, their effect on the physicochemical properties of the whole molecule, and the ability to form chelate complexes with metals.

For this reason, researchers have recently been focusing on the anticorrosion properties of substituted condensed bi-heterocyclic compounds, including those containing a triazole moiety as an articulated cycle [5, 6]. Thus, article [7] demonstrated that compounds of the 6-hydroxy-7-phenyl-6,7-dihydro-[1,2,4]triazolo[1,5-a]pyrimidin-5(4H)-one type appear to be effective mixed type corrosion inhibitors for steel. The inhibitory properties of $[1,2,4]$ triazolo $[4,3-b] 1,2,4$-triazipines were investigated in $[8,9]$ and it was determined that the structure of these compounds facilitates their adsorption on the surface of the protected metal. Although the adsorption mechanism is mainly electrostatic, the studied compounds significantly reduce the rate of acid corrosion of mild steel in phosphoric acid solutions. The paper [10] focuses on benzo[1,2,4]-triazolo[1,2,4]-triazinones and suggests that the inhibition effect of such compounds largely depends on their ability to form chelate complexes with copper atoms on the metal's surface due to the presence of oxybenzotriazine in the structure of the moiety. The effectiveness of the inhibitors of this type depends on the presence and the nature of additional substituents in the basic heterocyclic matrix. However, the number of studies focusing on the inhibitory properties of condensed polyheterocyclic compounds is still small. The purpose of our research was to study the anticorrosion properties of new derivatives of $[1,2,4]$ triazolo[1,5- $a]$ pyrimidine-6-carboxylates and determine whether they can be used as highly effective corrosion inhibitors for non-ferrous metals in neutral and acidic chloride environments.

\section{Experimental}

Structural formulas and possible tautomeric forms of the studied substances in water are presented in Table 1. Compounds a-e can exist in two tautomeric forms: pyrimidine and dihydropyrimidine. Tautomerism is not typical of compound $\mathbf{f}$.

Table 1. Inhibitor names, structures and tautomeric forms.

\begin{tabular}{cccc}
\hline Symbol & Name & Formula \\
Methyl 7-(2-methoxy-2- \\
oxoethyl)-[1,2,4]triazolo- \\
{$[1,5-a]$ pyrimidine-6- } \\
carboxylate
\end{tabular}




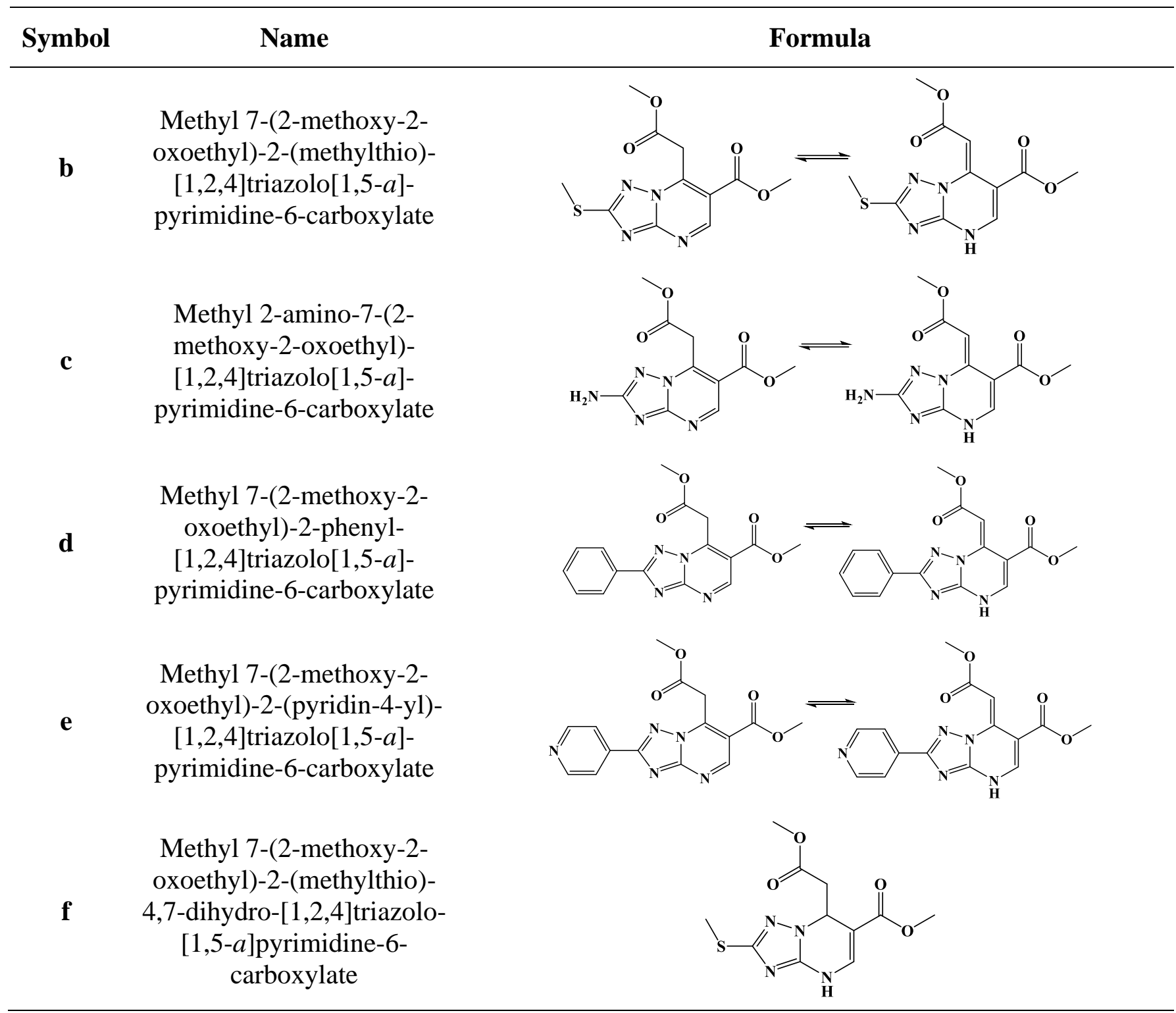

$[1,2,4]$ Triazolo[1,5-a]pyrimidine-6-carboxylates a-e were synthesized using the method described in [11]. The synthesis scheme is shown in Figure 1. Compound $\mathbf{f}$ was obtained according to a well-known procedure [12] (the scheme is shown in Figure 2). Other reagents and solvents were purchased from commercial sources and were used without additional purification.

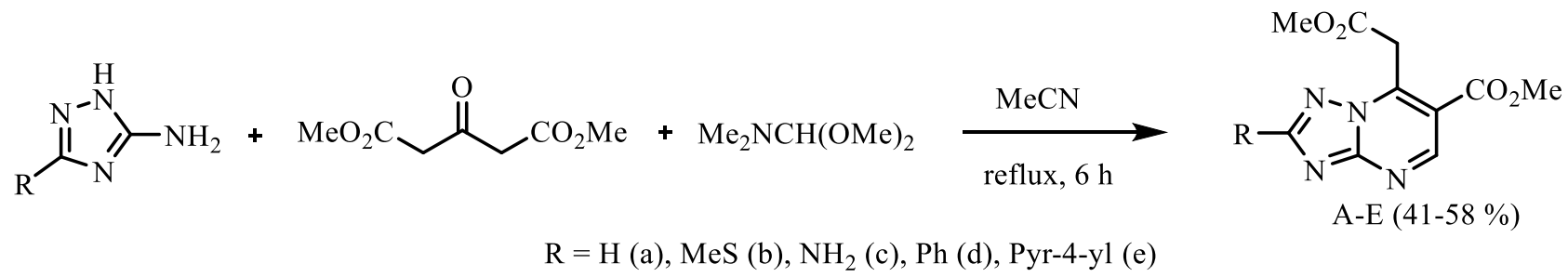

Figure 1. Compounds a-e synthesis scheme. 


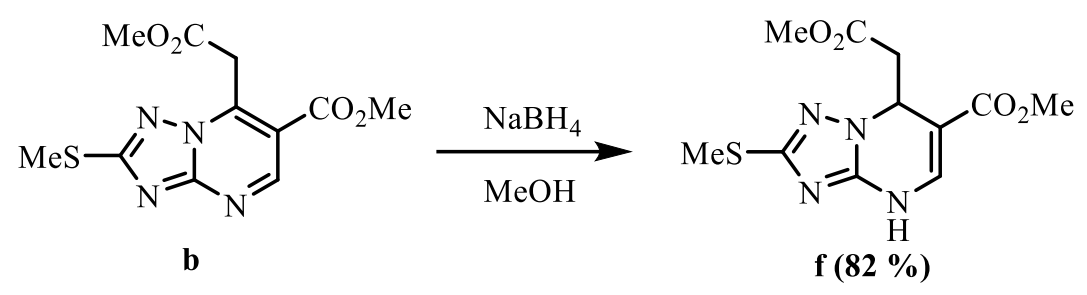

Figure 2. Compound $\mathbf{f}$ synthesis scheme.

Synthesis of [1,2,4]triazolo[1,5-a]pyrimidine-6-carboxylates (General method)

A mixture of the corresponding aminotriazole $(1.5 \mathrm{mmol}), \beta$-ketoglutaric acid dimethyl ester (2) $(313 \mathrm{mg}, 1.8 \mathrm{mmol})$, DMA DMF (3) $(214 \mathrm{mg}, 1.8 \mathrm{mmol})$ in $\mathrm{MeCN}$ (3 ml) was heated under reflux for $6 \mathrm{~h}$. After the completion of the reaction (TLC monitoring), the solvent was removed under reduced pressure, $i-\mathrm{PrOH}(6 \mathrm{ml})$ was added to the residue, the precipitate was filtered off and washed with $i-\mathrm{PrOH}$.

Methyl 7-(2-methoxy-2-oxoethyl)-[1,2,4]triazolo[1,5-a]pyrimidine-6-carboxylate (a). Yield $153 \mathrm{mg}(41 \%)$, white crystals, mp. $107-109^{\circ} \mathrm{C} .{ }^{1} \mathrm{H}$ NMR spectrum, $\delta$, ppm $(\mathrm{J}, \mathrm{Hz})$ : $3.66\left(3 \mathrm{H}, \mathrm{s}, \mathrm{CH}_{3} \mathrm{O}\right) ; 3.93\left(3 \mathrm{H}, \mathrm{s}, \mathrm{CH}_{3} \mathrm{O}\right) ; 4.77\left(2 \mathrm{H}, \mathrm{s}, \mathrm{CH}_{2} \mathrm{COOCH}_{3}\right) ; 8.87(1 \mathrm{H}, \mathrm{s}, \mathrm{H}-2) ;$. $(1 \mathrm{H}, \mathrm{s}, \mathrm{H}-5)$. Found, $m / z: 251.0781[\mathrm{M}+\mathrm{H}]^{+} . \mathrm{C}_{10} \mathrm{H}_{11} \mathrm{~N}_{4} \mathrm{O}_{4}$. Calculated, $m / z$ 251.0775.

Methyl 7-(2-methoxy-2-oxoethyl)-2-(methylthio)-[1,2,4]triazolo[1,5-a]pyrimidine-6carboxylate (b). Yield $218 \mathrm{mg}(49 \%)$, white crystals, mp. $121-123^{\circ} \mathrm{C} .{ }^{1} \mathrm{H}$ NMR spectrum, $\delta$, ppm $(J, \mathrm{~Hz}): 2.69\left(3 \mathrm{H}, \mathrm{s}, \mathrm{CH}_{3} \mathrm{~S}\right) ; 3.67\left(3 \mathrm{H}, \mathrm{s}, \mathrm{CH}_{3} \mathrm{O}\right) ; 3.91\left(3 \mathrm{H}, \mathrm{s}, \mathrm{CH}_{3} \mathrm{O}\right) ; 4.70(2 \mathrm{H}, \mathrm{s}$, $\left.\mathrm{CH}_{2} \mathrm{COOCH}_{3}\right) ; 9.20\left(1 \mathrm{H}, \mathrm{s}, \mathrm{H}-5\right.$.). Found, $m / z: 297.0646[\mathrm{M}+\mathrm{H}]^{+} . \mathrm{C}_{11} \mathrm{H}_{13} \mathrm{~N}_{4} \mathrm{O}_{4} \mathrm{~S}$. Calculated, $m / z 297.0653$.

Methyl 2-amino-7-(2-methoxy-2-oxoethyl)-[1,2,4]triazolo[1,5-a]pyrimidine-6carboxylate (c). Yield $175 \mathrm{mg}(44 \%)$, white crystals, mp. 207-209 ${ }^{\circ} \mathrm{C} .{ }^{1} \mathrm{H}$ NMR spectrum, $\delta$, ppm $(J, \mathrm{~Hz}): 3.63\left(3 \mathrm{H}, \mathrm{s}, \mathrm{CH}_{3} \mathrm{O}\right) ; 3.85\left(3 \mathrm{H}, \mathrm{s}, \mathrm{CH}_{3} \mathrm{O}\right) ; 4.56\left(2 \mathrm{H}, \mathrm{s}, \mathrm{CH}_{2} \mathrm{COOCH}_{3}\right) ; 6.89$ $\left(2 \mathrm{H}, \mathrm{s}, \mathrm{NH}_{2}\right) ; 8.92\left(1 \mathrm{H}, \mathrm{s}, \mathrm{H}-5\right.$.). Found, $m / z: 266.0880[\mathrm{M}+\mathrm{H}]^{+} . \mathrm{C}_{10} \mathrm{H}_{11} \mathrm{~N}_{5} \mathrm{O}_{4}$. Calculated, $m / z 266.0884$.

Methyl 7-(2-methoxy-2-oxoethyl)-2-phenyl-[1,2,4]triazolo[1,5-a]pyrimidine-6carboxylate (d). Yield $283 \mathrm{mg}(58 \%)$, white crystals, mp. $176-178^{\circ} \mathrm{C} .{ }^{1} \mathrm{H}$ NMR spectrum, $\delta$, ppm $(J, \mathrm{~Hz}): 3.69\left(3 \mathrm{H}, \mathrm{s}, \mathrm{CH}_{3} \mathrm{O}\right) ; 3.94\left(3 \mathrm{H}, \mathrm{s}, \mathrm{CH}_{3} \mathrm{O}\right) ; 4.83\left(2 \mathrm{H}, \mathrm{s}, \mathrm{CH}_{2} \mathrm{COOCH}_{3}\right) ; 7.58-$ $7.61(3 \mathrm{H}, \mathrm{m}, \mathrm{H} \mathrm{Ph}) ; 8.25-8.27$ (2H, m, H Ph); 9.28 (1H, s, H-5.). Found, $m / z: 327.1091$ $[\mathrm{M}+\mathrm{H}]^{+} . \mathrm{C}_{16} \mathrm{H}_{15} \mathrm{~N}_{4} \mathrm{O}_{4}$. Calculated, $m / z: 327.1089$.

Methyl 7-(2-methoxy-2-oxoethyl)-2-(pyridin-4-yl)-[1,2,4]triazolo[1,5-a] pyrimidine6-carboxylate (e). Yield $270 \mathrm{mg}(55 \%)$, white crystals, mp. $202-204^{\circ} \mathrm{C} .{ }^{1} \mathrm{H}$ NMR spectrum, $\delta$, ppm (J, Hz): $3.67\left(3 \mathrm{H}, \mathrm{s}, \mathrm{CH}_{3} \mathrm{O}\right) ; 3.92\left(3 \mathrm{H}, \mathrm{s}, \mathrm{CH}_{3} \mathrm{O}\right) ; 4.81\left(2 \mathrm{H}, \mathrm{s}, \mathrm{CH}_{2} \mathrm{COOCH}_{3}\right) ; 8.13$ $(2 \mathrm{H}, \mathrm{d}, \mathrm{J}=6.0, \mathrm{H} \mathrm{Ar}) ; 8.79$ (2H, d, J =6.0, H Ar); 9.30 (1H, s, H-5.). Found, $m / z: 328.1046$ $[\mathrm{M}+\mathrm{H}]^{+} . \mathrm{C}_{15} \mathrm{H}_{13} \mathrm{~N}_{5} \mathrm{O}_{4}$. Calculated, $m / z: 328.1041$.

Methyl 2-(methylthio)-7-(2-methoxy-2-oxoethyl)-4,7-dihydro-[1,2,4]triazolo[1,5a]pyrimidine-6-carboxylate (f). 
A mixture of methyl 7-(2-methoxy-2-oxoethyl)-2-(methylthio)-[1,2,4]triazolo[1,5a]pyrimidine-6-carboxylate (b) $(270 \mathrm{mg}, 0.9 \mathrm{mmol})$ and $\mathrm{NaBH}_{4}(51 \mathrm{mg}, 1.35 \mathrm{mmol})$ in $\mathrm{MeOH}(10 \mathrm{ml})$ was heated under reflux for $2 \mathrm{~h}$ (TLC monitoring). After the completion of the reaction, the mixture was cooled and $\mathrm{H}_{2} \mathrm{O}(30 \mathrm{ml})$ was added, the formed precipitate was filtered off and recrystallized from $i$-PrOH-DMF, 6:1 mixture. Yield $220 \mathrm{mg}(82 \%)$, white crystals, mp. $174-176^{\circ} \mathrm{C} .{ }^{1} \mathrm{H}$ NMR spectrum, $\delta, \mathrm{ppm}(\mathrm{J}, \mathrm{Hz}): 2.44\left(3 \mathrm{H}, \mathrm{s}, \mathrm{CH}_{3} \mathrm{~S}\right) ; 2.75(1 \mathrm{H}$, $\left.\mathrm{dd}, \mathrm{J}=15.5, \mathrm{~J}=5.4, \mathrm{CH}_{2} \mathrm{COOCH}_{3}\right) ; 2.95\left(1 \mathrm{H}, \mathrm{dd}, \mathrm{J}=15.5, \mathrm{~J}=3.5, \mathrm{CH}_{2} \mathrm{COOCH}_{3}\right) ; 3.50(3 \mathrm{H}$, $\left.\mathrm{s}, \mathrm{CH}_{3} \mathrm{O}\right) ; 3.65\left(3 \mathrm{H}, \mathrm{s}, \mathrm{CH}_{3} \mathrm{O}\right) ; 5.50(1 \mathrm{H}, \mathrm{dd}, \mathrm{J}=5.1, \mathrm{~J}=3.6, \mathrm{H}-7) ; 7.43(1 \mathrm{H}, \mathrm{s}, \mathrm{H}-5) ; 10.80$ (1H, s, NH). Found, $m / z: 299.0813[\mathrm{M}+\mathrm{H}]^{+} . \mathrm{C}_{11} \mathrm{H}_{14} \mathrm{~N}_{4} \mathrm{O}_{4} \mathrm{~S}$. Calculated, $m / z: 299.0809$.

To evaluate the efficiency of the corrosion inhibition properties of the studied compounds, a set of electrochemical and field corrosion testing methods was used. Quantum-chemical calculations were also performed.

Electrochemical measurements were performed at room temperature $\left(\sim 25^{\circ} \mathrm{C}\right)$ on copper (M1) electrodes in an unstirred borate buffer aqueous solution $(\mathrm{pH}$ 7.4) with natural aeration, in the presence of the inhibitor and $10 \mathrm{mM} \mathrm{NaCl}$. A classical electrolytic threeelectrode cell without separation of anode and cathode compartments was used in order to accelerate transient measurements.

A saturated silver chloride reference electrode was placed in a separate container linked to the electrolytic cell by an agar-agar-based salt bridge filled with a potassium nitrate saturated solution. The auxiliary electrode was a platinum gauze. The working copper electrode was polished by K3000 sandpaper, degreased in $96 \%$ ethanol, and washed with distilled water. The potentials of the working electrode $(E)$ are given according to the standard hydrogen electrode (SHE) scale. The current density $i$ was calculated by dividing the actual current $I$ by the geometric area of the working electrode $\left(0.75 \mathrm{~cm}^{2}\right)$.

Electrochemical measurements were performed using an IPC-PRO potentiostat (Frumkin Institute of Physical Chemistry and Electrochemistry Russian Academy of Sciences). In order to remove an oxide film, the working $\mathrm{Cu}$-electrode was cathodically prepolarised at $E=-0.60 \mathrm{~V}$ for 15 minutes prior to the experiment. The electrode was then held in the solution for about 3 to 5 minutes until the corrosion potential $\left(E_{\text {cor }}\right)$ stabilized. $\mathrm{An} \mathrm{NaCl}$ solution was then added to the working solution while stirring, so that the concentration of chloride ions would be $C_{\mathrm{Cl}^{-}}=10 \mathrm{mM}$. The studied inhibitors were also added to the solution at concentrations of $C_{\mathrm{inh}}=0.01,0.10$ and $1.00 \mathrm{mM}$. After the new $E_{\mathrm{cor}}$ value was established, the polarization curve was registered by scanning the potential towards either the anode or the cathode at $0.2 \mathrm{mV} / \mathrm{sec}$. The activation potential $\left(E_{\text {act }}\right)$ was identified by a rapid increase in the current on the anode polarization curve. Pits were then visually identified on the surface of the electrode. The measurement error for $E_{\text {act }}$ was below $0.03 \mathrm{~V}$.

The rate of corrosion in current units $\left(i_{\text {corr }}\right)$ was determined by the polarization resistance technique as summarized by Mansfeld [13].

The effectiveness of the inhibition activity of the substituted benzo-[1,2,4]-triazolo$[1,2,4]$-triazines $(\mathbf{a}-\mathbf{f})$ was evaluated by the degree of protection: 


$$
Z_{\mathrm{i}}=\frac{i_{\mathrm{cor}, 0}-i_{\mathrm{cor}, \mathrm{inh}}}{i_{\mathrm{cor}, 0}} \cdot 100 \%
$$

where $i_{\text {cor }, 0}$ and $i_{\text {cor,inh }}$ are the corrosion current densities with and without an inhibitor respectively.

A field corrosion testing was carried out on copper plates with a surface area of $S=20 \times 50 \mathrm{~mm}^{2}$ and a thickness of $d=0.10 \mathrm{~mm}$, which were preliminarily polished with K3000 sandpaper and degreased in acetone.

The experiments that lasted for $t=7$ days were carried out on three samples in an unstirred naturally aerated $1 \% \mathrm{HCl}$ solution. The plates were then washed with distilled water and treated according to GOST 9.907-83 "Methods for the removal of corrosion products after corrosion tests". The corrosion rate was determined according to the weight loss of the samples and calculated using the equation:

$$
k_{\text {inh }}=\frac{m_{0}-m}{S t},
$$

where $m_{0}$ and $m$ is the weight of the sample before and after the corrosion tests, respectively; $S$ is the total area of the plate, $\mathrm{m}^{2}$; and $t$ is the experiment time, days.

The inhibition efficiency of $[1,2,4]$ triazolo[1,5-a]pyrimidine-6-carboxylates was evaluated by the value of the inhibition factor:

$$
\gamma=\frac{k_{0}}{k_{\text {inh }}}
$$

and the degree of protection:

$$
Z_{\mathrm{k}}=\frac{\left(k_{0}-k_{\mathrm{inh}}\right)}{k_{0}} \cdot 100 \%,
$$

where $k_{0}$ and $k_{\text {inh }}$ are the rates of corrosion in the $\mathrm{HCl}$ solution with and without the inhibitor respectively. The parameter $k_{0}$ was $20 \mathrm{~g} \cdot \mathrm{m}^{-2} \cdot$ day $^{-1}$.

All the synthesized molecules and their isomeric (tautomeric) forms (except $\mathbf{f}$ ) are fully optimized using density functional theory (DFT) with B3LYP functional using 6-31G $(\mathrm{d}, \mathrm{p})$ basis set in Gaussian soft [14]. The optimized geometries show non-negative frequencies which results in molecules are located at minimum energy in potential energy surface. The determination of HOMO, LUMO energies and energy gap along with ionization potential, electron affinity, electronegativity $(\chi)$, absolute hardness $(\eta)$ and softness $(\sigma)$ for all the molecules were carried out at same level of theory.

From density functional theory the absolute hardness $(\eta)$ is defined as [15]

$$
\eta=\frac{1}{2} \frac{\partial \mu}{\partial N}=\frac{1}{2} \frac{\partial^{2} E}{\partial N^{2}}
$$


where $\mu$ is the chemical potential and $N$ is the number of electron and $E$ is the energy. R.G. Pearson has proposed an operational definition for absolute hardness as

$$
\eta=\frac{I P-E A}{2},
$$

where $I P$ and $E A$ are ionization energy and electron affinity, respectively. Also, from Koopman's theorem, $I P$ and $E A$ are defined as

$$
I P=-E_{\mathrm{HOMO}} ; E A=-E_{\mathrm{LUMO}}
$$

$E_{\text {Номо }}$ and $E_{\text {LUMо }}$ are the energies of highest occupied and lowest unoccupied molecular orbitals. Thus, the hardness $(\eta)$ is a measure of resistance to change of electron cloud of chemical system. The softness $(\sigma)$ is reciprocal of the hardness, and it is an important parameter of reaction chemistry as most of the reactive species have higher softness value. Electronegativity $(\chi)$ is defined in terms of energies of HOMO and LUMO as

$$
\chi=\frac{I P+E A}{2}
$$

\section{Results and Discussion}

The solubility of methyl-7-(2-methoxy-2-oxoethyl)-2-(pyridine-4-yl)-[1,2,4]triazolo[1,5a]pyrimidine-6-carboxylate (e) did not exceed $0.05 \mathrm{mM}$ under the conditions of the experiment. Therefore, we could not study its inhibitory properties.

The introduction of $\mathbf{a}, \mathbf{b}$, and $\mathbf{d}$ shifts the open circuit potential in the cathodic direction by $\sim 20-41 \mathrm{mV}$ in the entire concentration range (Figure $3 a, b, d$ ). The addition of $\mathbf{c}, \mathbf{f}$ results in no obvious changes in $E_{\text {cor }}$ (Figure $3 c, f$ ): with a concentration of $0.01-0.10 \mathrm{mM}$ there was either no change as compared to the control measurement, or a shift to the anodic region by $\sim 20-30 \mathrm{mV}$; when the concentration was increased up to $1.00 \mathrm{mM}$, a shift to the cathodic region by $\sim 40-70 \mathrm{mV}$ was observed. When a protective effect is observed, compounds a, $\mathbf{b}$, and $\mathbf{d}$ can be considered as mixed type inhibitors [16], while compounds $\mathbf{c}$ and $\mathbf{f}$ with the concentration of $1.00 \mathrm{mM}$ predominantly affect the cathodic half-reaction.

The polarization curves obtained in the presence of triazolopyrimidines $\mathbf{a}, \mathbf{b}$, and $\mathbf{c}$ (Figure $3 a-c$ ) are similar in the studied concentration range. When $C_{\mathrm{inh}}=0.01-0.10 \mathrm{mM}$, the cathodic current density decreases by $\sim 20-30 \%$ as compared to the control test performed with the same values of the electrode potential. On the anodic polarization curves, the maximum current density was formed in the potential region of $0.25-0.35 \mathrm{~V}$. The height of the maximum for $\mathbf{a}, \mathbf{b}$, and $\mathbf{c}$ with $C_{\mathrm{inh}}=0.01-0.10 \mathrm{mM}$ exceeded the value for the control test. When the concentration was increased up to $1.00 \mathrm{mM}$, as well as in the presence of $\mathbf{d}$ and $\mathbf{f}$, the maximum current density did not exceed the control value. 


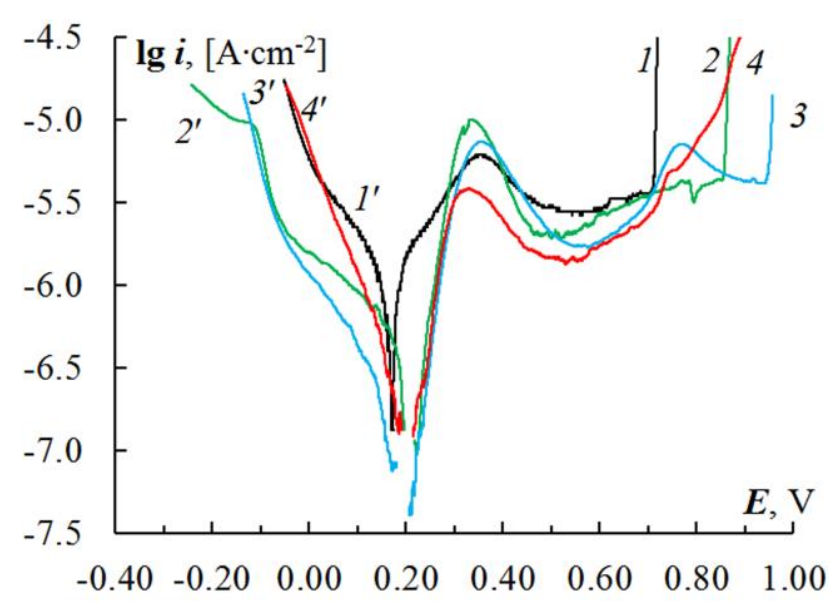

(a)

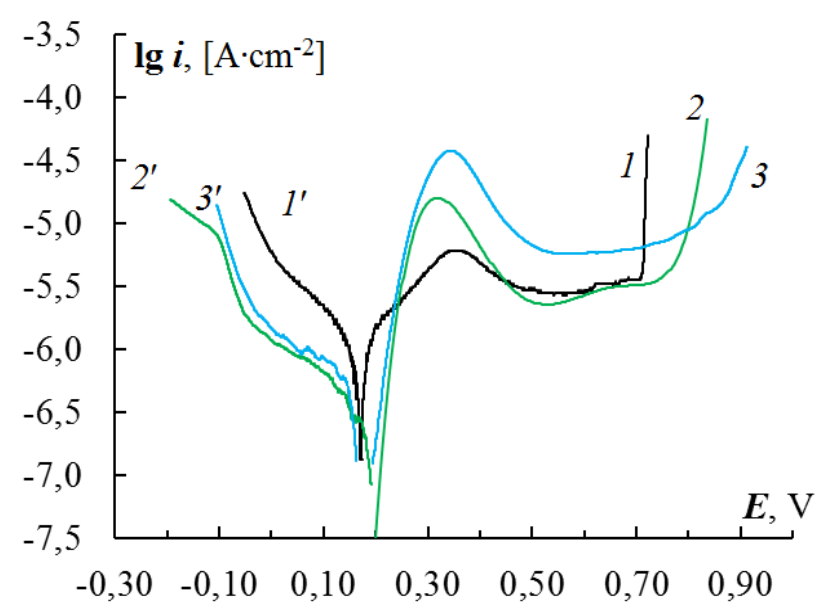

(c)

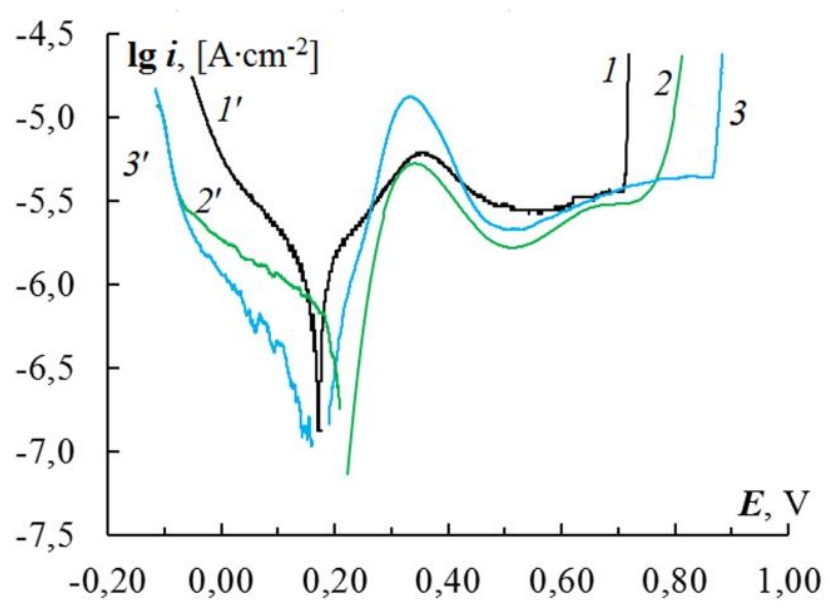

(b)

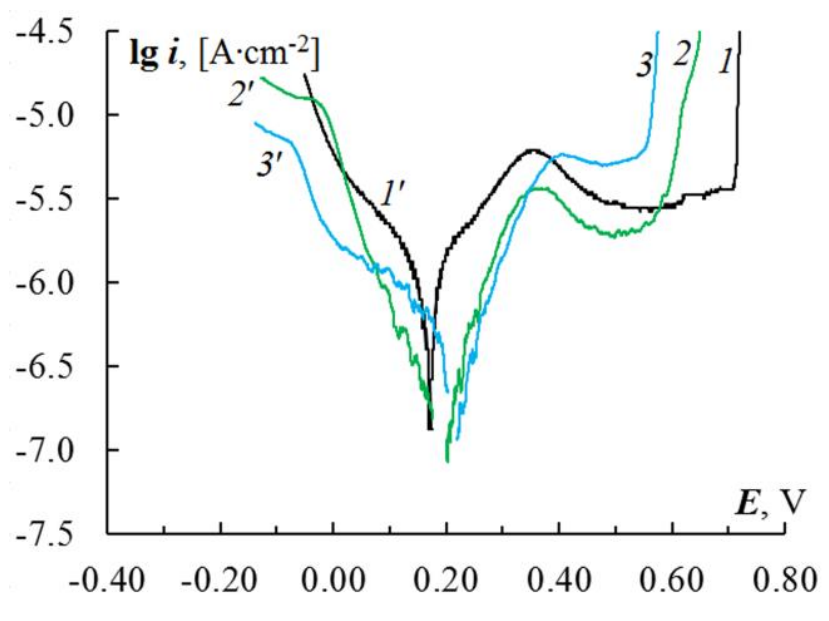

(d)

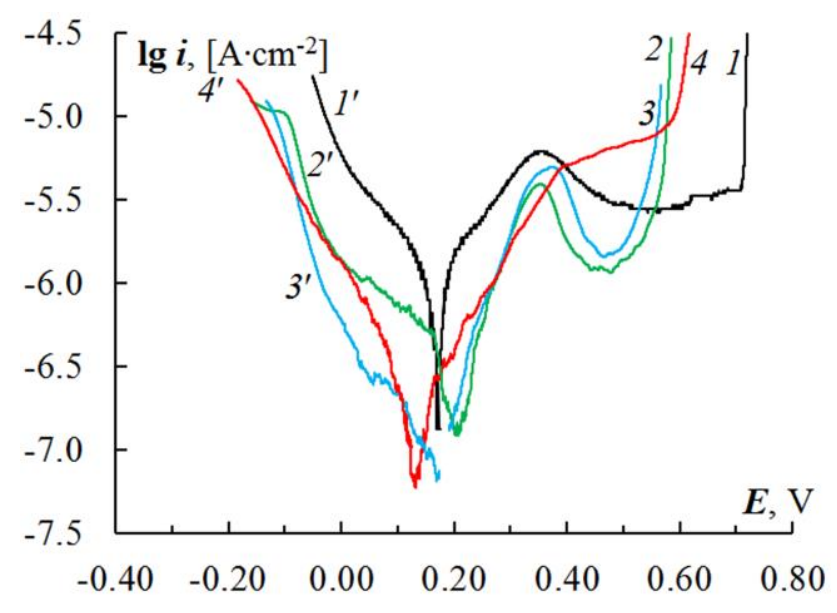

(f)

Figure 3. Anodic $(1-4)$ and cathodic $\left(1^{\prime}-4^{\prime}\right)$ polarization curves of copper in borate buffer $(\mathrm{pH} 7.4)+10 \mathrm{mM} \mathrm{NaCl}$ without an inhibitor $\left(1,1^{\prime}\right)$ and in the presence of compounds $\mathbf{a}(\mathrm{a}), \mathbf{b}$ (b), c (c), d (d), and f (f) with concentrations of 0.01 (2), 0.10 (3), and $1.00 \mathrm{mM}$ (4). 
The activation potential shifted to the anodic region by $150-250 \mathrm{mV}$ for compounds $\mathbf{a}-\mathbf{c}$. Compounds $\mathbf{d}$ and $\mathbf{f}$ facilitated the shift of $E_{\text {act }}$ to the cathodic region by $50-100 \mathrm{mV}$ as compared to the control test.

Based on the data presented on the total polarization curves and the calculations of the corrosion rate of copper by means of polarization resistance technique (Table 2) we determined that all the studied compounds inhibit copper corrosion in a neutral chloride solution. Generally, the degree of protection grows monotonously with an increase in the inhibitor concentration. The only exception is 2 -amino-[1,2,4]triazole[1,5-a]pyrimidine-6carboxylate (c): the degree of protection decreases with an increase in the concentration of the inhibitor. The greatest inhibition effect was observed in the presence of methylmercaptoderivatives of triazolopyrimidines (compounds $\mathbf{b}$ and $\mathbf{f}$ ). At $C_{\mathrm{inh}}=1.00 \mathrm{mM}$, the degree of protection is up to $91.7 \%$ and $86.7 \%$, respectively.

Table 2. Open circuit potential, polarization resistance, corrosion current density, and degree of protection of copper electrode in $0.01 \mathrm{M} \mathrm{NaCl}$ solutions with different derivatives of $[1,2,4]$ triazolo[1,5- $a]$ pyrimidine6-carboxylates.

\begin{tabular}{|c|c|c|c|c|c|}
\hline Inhibitor & $\begin{array}{c}\text { Concentration } \\
\text { of the inhibitor, } \\
C_{\text {inh }}, \mathbf{m M}\end{array}$ & $\begin{array}{c}\text { Corrosion } \\
\text { potential, } E_{\mathrm{cor}}, \\
\mathrm{V}\end{array}$ & $\begin{array}{c}\text { Polarization } \\
\text { resistance, } R_{\mathrm{p}}, \\
\mathrm{k} \Omega \cdot \mathrm{cm}^{2}\end{array}$ & $\begin{array}{c}\text { Corrosion } \\
\text { rate, } i_{\text {cor, }}, \\
\mu \mathrm{A} \cdot \mathbf{c m}^{-2}\end{array}$ & $\begin{array}{c}\text { Degree of } \\
\text { protection, } \\
Z_{i}, \%\end{array}$ \\
\hline none & - & 0.172 & $41.9 \pm 4.6$ & $1.2 \pm 0.3$ & - \\
\hline \multirow{3}{*}{$\mathbf{a}$} & 0.01 & 0.211 & $59.5 \pm 6.6$ & $0.78 \pm 0.13$ & 35.0 \\
\hline & 0.10 & 0.198 & $130 \pm 27$ & $0.44 \pm 0.10$ & 63.3 \\
\hline & 1.00 & 0.194 & $141 \pm 23$ & $0.43 \pm 0.09$ & 64.2 \\
\hline \multirow{2}{*}{ b } & 0.01 & 0.210 & $35.2 \pm 7.1$ & $1.07 \pm 0.09$ & 10.8 \\
\hline & 0.10 & 0.175 & $62.3 \pm 14.2$ & $0.10 \pm 0.03$ & 91.7 \\
\hline \multirow{2}{*}{ c } & 0.01 & 0.176 & $14.6 \pm 5.7$ & $0.67 \pm 0.03$ & 44.2 \\
\hline & 0.10 & 0.186 & $34.1 \pm 12.2$ & $0.91 \pm 0.09$ & 24.2 \\
\hline \multirow{2}{*}{ d } & 0.10 & 0.213 & $86.4 \pm 12.3$ & $0.89 \pm 0.05$ & 25.8 \\
\hline & 1.00 & 0.198 & $108 \pm 29$ & $0.28 \pm 0.06$ & 76.7 \\
\hline \multirow[t]{2}{*}{ e } & - & - & - & - & - \\
\hline & 0.01 & 0.200 & $81.3 \pm 12.4$ & $0.76 \pm 0.20$ & 36.7 \\
\hline \multirow[t]{2}{*}{ f } & 0.10 & 0.169 & $146 \pm 30$ & $0.29 \pm 0.06$ & 75.8 \\
\hline & 1.00 & 0.124 & $154 \pm 28$ & $0.16 \pm 0.05$ & 86.7 \\
\hline
\end{tabular}

The results of the test in an acidic chloride environment (Table 3) are similar to the experiments in neutral aqueous electrolyte solutions. Thus, the obtained values of $Z_{\mathrm{k}}$ mostly correlate with the corresponding values of $Z_{\mathrm{i}}$. An increase in the protective properties of the inhibitors is observed in the $\mathbf{a}-\mathbf{c}-\mathbf{d}-\mathbf{f}-\mathbf{b}$ series. The greatest effect is observed, when a MeS 
moiety is introduced in the structure of the inhibitor. Similar protective properties were observed in alkylmercapto derivatives of aminotriazoles with regard to copper and copperbased alloys (namely brass) in $[17,18]$. Thus, the results obtained in our study comply with the existing literature.

Table 3. Results of the copper natural corrosion tests.

\begin{tabular}{|c|c|c|c|c|}
\hline Inhibitor & $\begin{array}{c}\text { Concentration of } \\
\text { the inhibitor } C_{\text {inh }} \text {, } \\
\text { mM }\end{array}$ & $\begin{array}{c}\text { Corrosion rate } k, \\
\mathbf{g} \cdot \mathbf{m}^{2} \cdot \mathbf{d a y}^{-1}\end{array}$ & $\begin{array}{c}\text { Inhibition factor, } \\
\gamma\end{array}$ & $\begin{array}{c}\text { Degree of } \\
\text { protection } Z_{k}, \%\end{array}$ \\
\hline none & - & 19.2 & - & - \\
\hline \multirow{3}{*}{$\mathbf{a}$} & 0.01 & 16.0 & 1.2 & 16.6 \\
\hline & 0.10 & 14.5 & 1.3 & 24.9 \\
\hline & 1.00 & 9.1 & 2.1 & 52.9 \\
\hline \multirow{3}{*}{ b } & 0.01 & 11.3 & 1.7 & 41.0 \\
\hline & 0.10 & 2.7 & 7.1 & 85.9 \\
\hline & 1.00 & 2.4 & 5.8 & 82.8 \\
\hline \multirow{3}{*}{ c } & 0.01 & 7.1 & 2.7 & 63.3 \\
\hline & 0.10 & 6.1 & 3.2 & 68.5 \\
\hline & 1.00 & 1.3 & 14.5 & 93.1 \\
\hline \multirow{3}{*}{ d } & 0.01 & 16.4 & 1.2 & 14.5 \\
\hline & 0.10 & 14.8 & 1.3 & 23.1 \\
\hline & 1.00 & 4.7 & 3.1 & 67.3 \\
\hline \multirow[t]{2}{*}{ e } & - & - & - & - \\
\hline & 0.01 & 11.0 & 1.8 & 43.0 \\
\hline \multirow[t]{2}{*}{ f } & 0.10 & 4.3 & 4.5 & 77.5 \\
\hline & 1.00 & 2.3 & 6.1 & 83.6 \\
\hline
\end{tabular}

We assume that the ability of the studied compounds to passivate non-ferrous metals is accounted for by the presence of an acidic NH-proton of the dihydropyrimidine cycle [19]. This is why it is possible for inhibitor films to be formed on the metal's surface that are complex salts with copper atoms (Figure 4).

The formation of such complexes is described in detail in [20]. Using physical research methods Yu.I. Kuznetsov et al. determined that 3-R-5-amino-1H-[1,2,4]-triazoles form such complexes due to the presence of an endocyclic NH-proton. Such complexes formed by the inhibitors with copper have a high capacity for chemisorption on the metal's surface, which facilitates the formation of self-organizing protective layers. This accounts for the inhibitory effect of compounds with such a structure. 


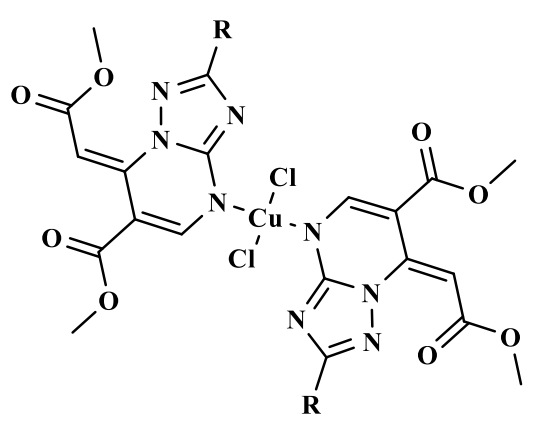

Figure 4. Complex based on $[1,2,4]$ triazolo $[1,5-a]$ pyrimidine-6-carboxylates with $\mathrm{Cu}^{2+}$ ions .

Additional corrosion tests were performed to test the suggested inhibition mechanism using commercially available 7-(4-chlorophenyl)-[1,2,4]triazolo[1,5-a]pyrimidine. Its pyrimidine cycle is completely dehydrated and prototropic tautomerism is impossible, there are no mobile acidic NH-protons that can form covalent bonds with metal atoms, which is required for a complex formation. In the presence of 7-(4-chlorophenyl)-[1,2,4]triazolo[1,5a]pyrimidine, the corrosion intensified in an acidic chloride environment within the concentration range of $0.003-0.300 \mathrm{mM}$ (Table 4), which means that the compound cannot be used as an inhibitor.

Table 4. Results of the natural corrosion tests performed on copper in the presence of 7-(4-chlorophenyl)$[1,2,4]$ triazolo[1,5-a]pyrimidine.

\begin{tabular}{|c|c|c|c|c|}
\hline Inhibitor & $\begin{array}{c}\text { Concentration of } \\
\text { the inhibitor } C_{\text {inh, }} \\
\text { mM }\end{array}$ & $\begin{array}{c}\text { Corrosion rate } k, \\
\mathbf{g} \cdot \mathbf{m}^{2} \cdot \mathbf{d a y}^{-1}\end{array}$ & $\begin{array}{c}\text { Inhibition factor, } \\
\gamma \gamma\end{array}$ & $\begin{array}{c}\text { Degree of } \\
\text { protection } Z_{\mathrm{k}}, \%\end{array}$ \\
\hline & 0.003 & 29.2 & 0.7 & -52.0 \\
\hline & 0.030 & 31.0 & 0.6 & -61.1 \\
\hline & 0.300 & 33.0 & 0.6 & -71.5 \\
\hline
\end{tabular}

Thus, the chemical structure of the synthesised compounds facilitates their chemisorption on the metal's surface. This happens due to the formation of complexes with the atoms of the metal's surface, which is impossible for a similar aromatic triazolopyrimidine matrix of the commercial analogue. This also explains the similar inhibitory effects demonstrated by compounds $\mathbf{b}$ and f. The latter initially contains dihydropyrimidine moiety capable of complex formation. We should also note that the suggested hypothesis explains the fact that the inhibitory effect of the studied compounds is observed in the dihydropyrimidine tautomeric state. This is why when performing quantum chemical calculations, it was a priority to determine the most energetically favourable tautomeric state for compounds $\mathbf{a}-\mathbf{e}$. 
$a_{1}$

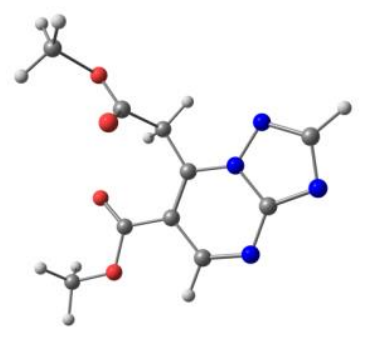

$b_{1}$

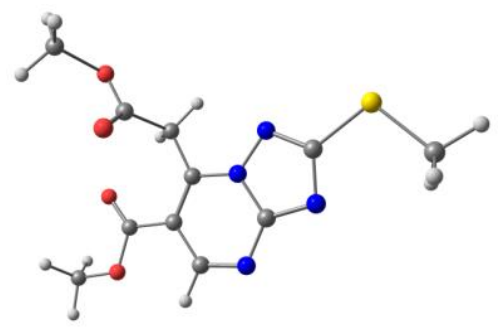

$\mathrm{C}_{1}$

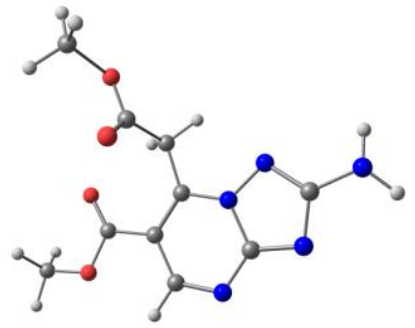

$d_{1}$

$\mathbf{e}_{1}$
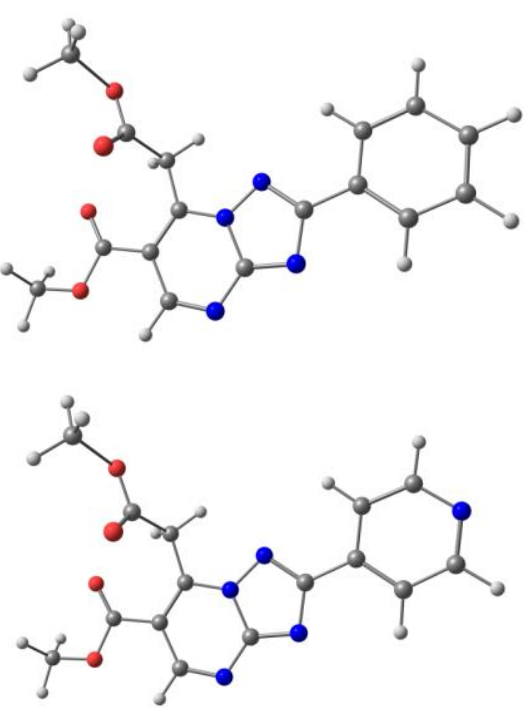

$a_{2}$

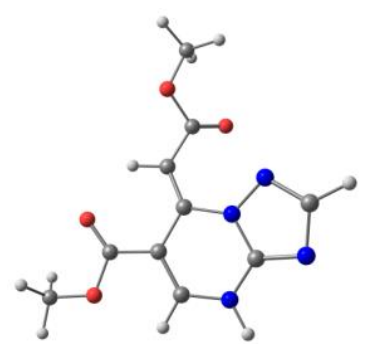

$b_{2}$

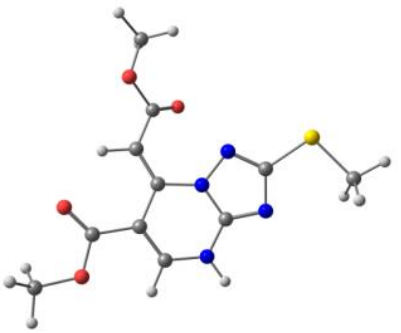

$c_{2}$

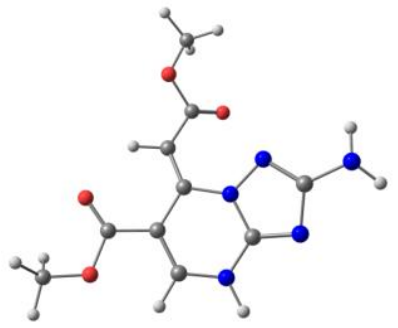

$d_{2}$

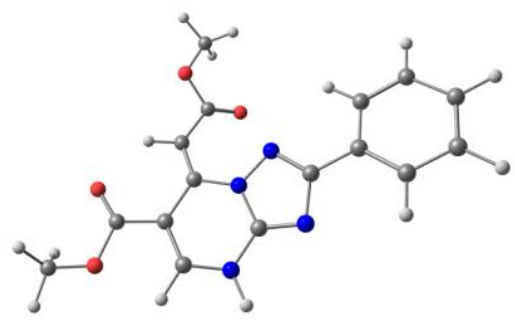

$e_{2}$

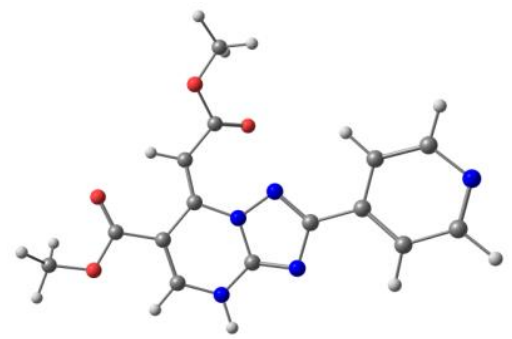

f

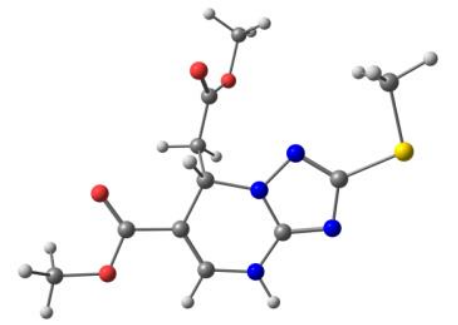

Figure 5. Optimised structures of the molecules considered for the study. 
The optimized structures of molecules and their tautomer with relative energies are shown in Figure 5 and Table 5. As shown in table 5, the $1^{\text {st }}$ isomers $\left(i . e ., \mathbf{a}_{\mathbf{1}}, \mathbf{b}_{\mathbf{1}}, \mathbf{c}_{\mathbf{1}}, \mathbf{d}_{\mathbf{1}}\right.$ and $\mathbf{e}_{\mathbf{1}}$, pyrimidine form) are more stable than the corresponding $2^{\text {nd }}$ isomers (i.e., $\mathbf{a}_{2}, \mathbf{b}_{2}, \mathbf{c}_{2}, \mathbf{d}_{\mathbf{2}}$ and $\mathbf{e}_{2}$, dihydropyrimidine form) and the differences between them are in the range of 15$18 \mathrm{kcal} / \mathrm{mol}$. However, these results of energy calculating do not exclude the possibility of tautomerism under the conditions studied.

It is known that the ability of inhibitors to interact with a metal surface increases with an increase in HOMO and a decrease in LUMO [21]. The smaller the HOMO-LUMO gap, the higher the reactivity of the inhibitor to the metal surface and the stronger the inhibitory effect. The calculated HOMO, LUMO energies, HOMO-LUMO gap (HLG), ionization potential, electron affinity, electronegativity $(\chi)$, absolute hardness $(\eta)$ and softness $(\sigma)$ in $\mathrm{eV}$ are tabulated in Table 5.

Table 5. Calculated energies of HOMO, LUMO, HOMO LUMO gap (HLG), ionization potential (IP), electron affinity $(E A)$, electronegativity $(\chi)$, absolute hardness $(\eta)$ and softness $(\sigma)$ in $\mathrm{eV}$ at B3LYP/6-31+ $\mathrm{G}(\mathrm{d}, \mathrm{p})$ level.

\begin{tabular}{cccccccccc}
\hline Symbol & $\begin{array}{c}\text { Energy, } \\
\text { kcal/mol }\end{array}$ & HOMO & LUMO & HLG & IP & EA & $\chi$ & $\boldsymbol{\eta}$ & $\boldsymbol{\sigma}$ \\
\hline $\mathbf{a}_{1}$ & 0.00 & -7.10 & -2.05 & 5.05 & 7.10 & 2.05 & 4.58 & 2.52 & 0.40 \\
$\mathbf{a}_{2}$ & 15.24 & -5.81 & -1.61 & 4.20 & 5.81 & 1.61 & 3.71 & 2.10 & 0.48 \\
$\mathbf{b}_{1}$ & 0.00 & -6.24 & -1.95 & 4.29 & 6.24 & 1.95 & 4.09 & 2.14 & 0.47 \\
$\mathbf{b}_{2}$ & 17.60 & -5.53 & -1.61 & 3.92 & 5.53 & 1.61 & 3.57 & 1.96 & 0.51 \\
$\mathbf{c}_{1}$ & 0.00 & -6.28 & -1.65 & 4.63 & 6.28 & 1.65 & 3.97 & 2.31 & 0.43 \\
$\mathbf{c}_{2}$ & 17.97 & -5.38 & -1.48 & 3.90 & 5.38 & 1.48 & 3.43 & 1.95 & 0.51 \\
$\mathbf{d}_{1}$ & 0.00 & -6.42 & -2.06 & 4.36 & 6.42 & 2.06 & 4.24 & 2.18 & 0.46 \\
$\mathbf{d}_{2}$ & 15.65 & -5.64 & -1.62 & 4.02 & 5.64 & 1.62 & 3.63 & 2.01 & 0.50 \\
$\mathbf{e}_{1}$ & 0.00 & -6.92 & -2.32 & 4.60 & 6.92 & 2.32 & 4.62 & 2.3 & 0.43 \\
$\mathbf{e}_{2}$ & 15.06 & -5.90 & -1.78 & 4.12 & 5.90 & 1.78 & 3.84 & 2.06 & 0.49 \\
$\mathbf{f}$ & & -5.70 & -1.34 & 4.36 & 5.70 & 1.34 & 3.52 & 2.18 & 0.46 \\
\hline
\end{tabular}

The calculated HLG for the $\mathbf{a}_{1}$ molecule is $5.05 \mathrm{eV}$ while that of its tautomer is $4.20 \mathrm{eV}$. Similarly, from the table it is observed that, for all the molecules the $2^{\text {nd }}$ isomer always shows smaller HLG as compared to the corresponding $1^{\text {st }}$ isomer. Among all the studied molecules the $\mathbf{a}_{1}$ molecule shows the highest HLG of $5.05 \mathrm{eV}$ while the $\mathbf{c}_{2}$ molecule shows the smallest HLG of $3.90 \mathrm{eV}$. The molecular orbital pictures of all the molecules are shown in Figure 6. A similar trend is observed for $\eta$ and $\chi$, i.e., the $2^{\text {nd }}$ isomer shows smaller $\eta$ and $\chi$ values compared to the corresponding $1^{\text {st }}$ isomer. While the opposite is true for $\sigma$, i.e. the $1^{\text {st }}$ isomer shows smaller $\sigma$ values compared to the corresponding $2^{\text {nd }}$ isomer. 


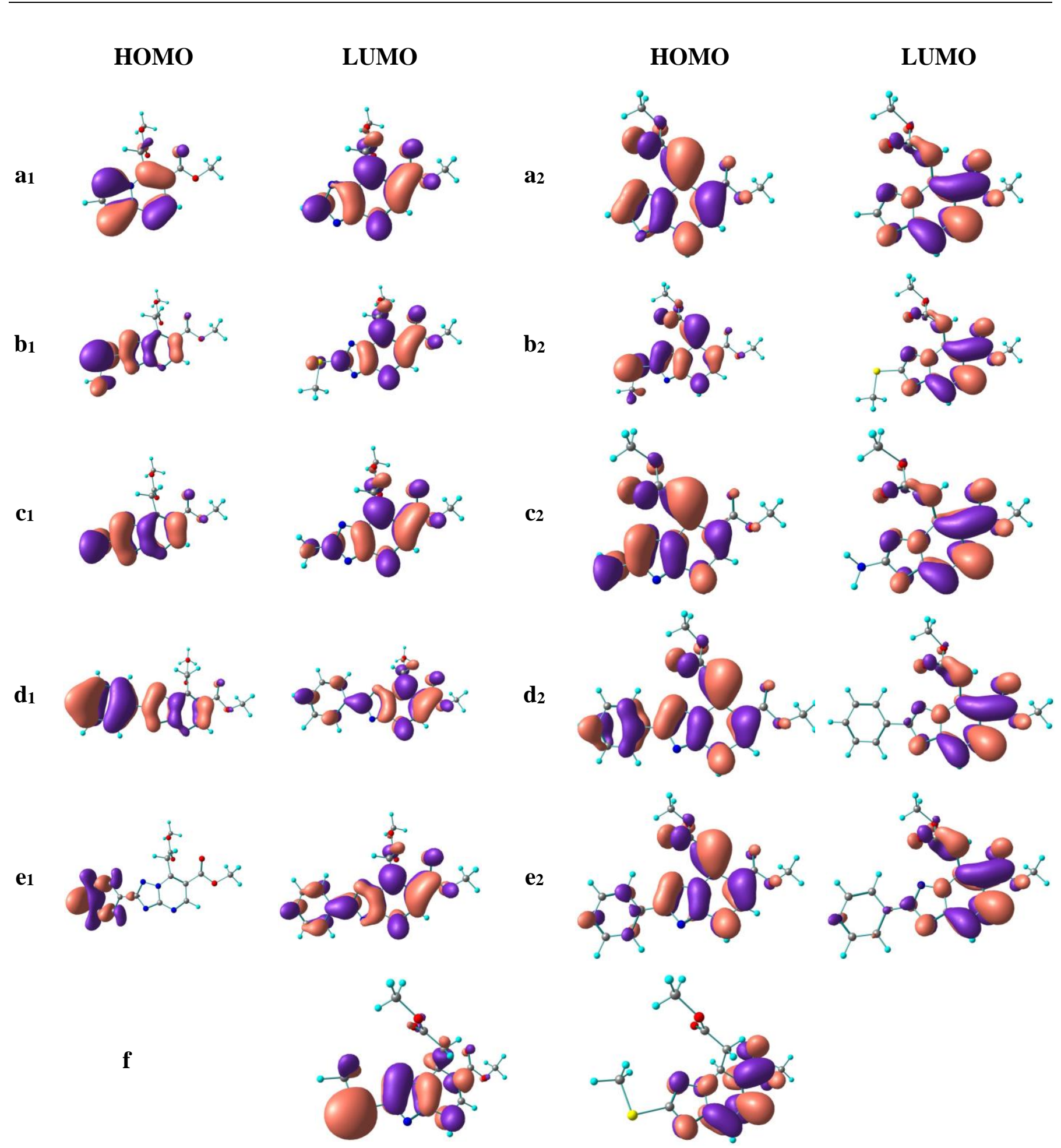

Figure 6. Molecular orbital pictures of molecules.

Thus, based on the results of the quantum mechanical calculations, we can say that the ability of the studied compounds to interact with the metal and their inhibitory effect should increase in the $\mathbf{f}-\mathbf{a}-\mathbf{e}-\mathbf{c}-\mathbf{d}-\mathbf{b}$ series. This assumption agrees with the results of the corrosion tests. The only exception is triazolopyrimidine f. It is possible, that its inhibitory effect (as 
well as the inhibitory effect of $\mathbf{b}$ ) is largely determined by the presence of a mercaptoalkyl substituent, which increases the chemisorption of the compound on the metal's surface. However, we did not focus on this inhibition mechanism in our calculations.

\section{Conclusion}

In our study we used field, electrochemical and quantum chemical methods to analyse the inhibitory properties of new synthesised derivatives of $[1,2,4]$ triazolo[ $[1,5-a]$ pyrimidine-6carboxylates with regard to the corrosion of copper in neutral and acidic chloride environments with concentrations of $0.01-1.00 \mathrm{mM}$.

The highest degree of protection in a neutral environment with the concentration of $1.00 \mathrm{mM}$ was observed in methyl 7-(2-methoxy-2-oxoethyl)-2-phenyl-[1,2,4]triazolo[1,5a]pyrimidine-6-carboxylate (76\%) and methyl 7-(2-methoxy-2-oxoethyl)-2-(methylthio)4,7-dihydro-[1,2,4]triazolo[1,5-a]pyrimidine-6-carboxylate $(86 \%)$, as well as in methyl 7(2-methoxy-2-oxoethyl)-2-(methylthio)-[1,2,4]triazolo[1,5-a]pyrimidine-6-carboxylate (91\%), when its concentration was $0.10 \mathrm{mM}$. In the acidic environment, the most effective inhibitors are methyl 7-(2-methoxy-2-oxoethyl)-2-(methylthio)-4,7-dihydro-[1,2,4]triazolo[1,5-a]pyrimidine-6-carboxylate (83\%) and methyl 2-amino-7-(2-methoxy-2-oxoethyl)$[1,2,4]$ triazolo[1,5-a]pyrimidine-6-carboxylate $(93 \%)$ with the concentration of $1.00 \mathrm{mM}$, and methyl 7-(2-methoxy-2-oxoethyl)-2-(methylthio)-[1,2,4]triazolo[1,5-a]pyrimidine-6carboxylate $(82-85 \%)$ with a concentration of $0.10-1.00 \mathrm{mM}$.

The article demonstrates that the protection mechanism of the studied inhibitors is based on their chemisorption on the metal's surface and formation of self-organizing protective layers by means of formation of complexes containing endocyclic NH-protons of the pyrimidine cycle.

The results obtained can be used to further modify the structure of triazolopyrimidine inhibitors of metal corrosion in order to enhance their protective effect.

\section{Acknowledgements}

The study was supported by the Russian Foundation for Basic Research, project no. 20-3380017.

\section{References}

1. M.A. Quraishi, D.S. Chauhan and V.S. Saji, Heterocyclic organic corrosion inhibitors: principles and applications, Elsevier, 2020. doi: 10.1016/C2018-0-04237-1

2. Yu.I. Kuznetsov and L.P. Kazansky, Physicochemical aspects of metal protection by azoles as corrosion inhibitors, Russ. Chem. Rev., 2008, 77, no. 3, 219-232. doi: 10.1070/RC2008v077n03ABEH003753

3. Yu.I. Kuznetsov, J.G.N. Thomas and A.D. Mercer, Organic inhibitors of corrosion of metals, Springer Science \& Business Media, 1996. doi: 10.1007/978-1-4899-1956-4 
4. Yu.I. Kuznetsov, N.N. Andreev and A.I. Marshakov, A. Physicochemical aspects of metal corrosion inhibition, Russ. J. Phys. Chem., 2020, 94, no. 3, 505-515. doi: 10.1134/S0036024420030152

5. S. Lahmidi, A. Elyoussfi, A. Dafali, H. Elmsellem, N.K. Sebbar, L. El Ouasif, A.E. Jilalat, B. El Mahi, E.M. Essassi, I. Abdel-Rahman and B. Hammouti, Corrosion inhibition of mild steel by two new 1,2,4-triazolo [1,5-a] pyrimidine derivatives in $1 \mathrm{M}$ HCl: Experimental and computational study, J. Mater. Environ. Sci., 2017, 8, no. 1, 225-237.

6. I.R. Saad, A.M. Abdel-Gaber, G.O. Younes and B. Nsouli, Corrosion Inhibition of Mild Steel in Acidic Solutions Using 1,2,4-Triazolo [1,5-a] pyrimidine, Russ. J. Appl. Chem., 2018, 91, no. 2, 245-252. doi: 10.1134/S107042721802012X

7. L. Guo, Y. El Bakri, R. Yu, J. Tan and E.M. Essassi, Newly synthesized triazolopyrimidine derivative as an inhibitor for mild steel corrosion in $\mathrm{HCl}$ medium: an experimental and in silico study, J. Mater. Res. Technol., 2020, 9, no. 3, 6568-6578. doi: $10.1016 /$ j.jmrt.2020.04.044

8. Y. El Bakri, Y. El Aoufir, H. Bourazmi, A. Harmaoui, J. Sebhaoui, M.H. Tabyaoui, A. Guenbour, H. Oudda, H. Lgaz, F. El Hajaji, A.B. Ali, Y. Ramli and E.M. Essassi, Corrosion control of carbon steel in phosphoric acid by 6-methyl-7H-1,2,4-triazolo [4,3b][1,2,4]-triazepine-8 (9H)-thione: Electrochemical studies, J. Mater. Environ. Sci., 2017, 8, no. 8, 2657-2666.

9. Y. El Bakri, L. Guo and E.M. Essassi, Electrochemical, DFT and MD simulation of newly synthesized triazolotriazepine derivatives as corrosion inhibitors for carbon steel in $1 \mathrm{M} \mathrm{HCl}$, J. Mol. Liq., 2019, 274, 759-769. doi: 10.1016/j.molliq.2018.11.048

10. D.S. Shevtsov, M.N.M. Mawlood, O.A. Kozaderov, Kh.S. Shikhaliev, A.A. Kruzhilin, A.Yu. Potapov, I.D. Zartsyn and Ch. Prabhakar, New copper corrosion inhibitors in chloride environments based on benzo-[1,2,4]-triazolo-[1,2]-triazinones, Int. J. Corros. Scale Inhib., 2021, 10, no. 1, 228-244. doi: 10.17675/2305-6894-2021-10-1-13

11. V.A. Polikarchuk, Yu.V. Chertova, A.Yu. Potapov, I.V. Ledenyova, Ye.A. Kosheleva, M.Yu. Krysin, O.A. Kozadyorov, G.V. Shatalov, D.Yu. Vandyshev, Kh.S. Shikhaliev and $\mathrm{Ch}$. Prabhakar, Novel variants of the multicomponent reaction for the synthesis of 1,2,4-triazolo[1,5- $a]$ pyrimidines and pyrido[3,4-e][1,2,4]triazolo[1,5- $a]$ pyrimidines, Chem. Heterocycl. Compd., 2020, 56, 1054-1061. doi: 10.1007/s10593-020-02773-7

12. S.M. Desenko and V.D. Orlov, Azageterotsikly na osnove aromaticheskikh nepredel'nykh ketonov (Azaheterocycles based on aromatic unsaturated ketones), Folio: Kharkov, 1998, 122 (in Russian).

13. F. Mansfeld, Tafel slopes and corrosion rates obtained in the pre-Tafel region of polarization curves, Corros. Sci., 2005, 47, no. 12, 3178-3186. doi: 10.1016/j.corsci.2005.04.012

14. M.J. Frisch, G.W. Trucks, H.B. Schlegel, G.E. Scuseria, M.A. Robb, J.R. Cheeseman, G. Scalmani, V. Barone, G.A. Petersson, H. Nakatsuji et al., Gaussian16 Revision B.01, Gaussian Inc. Wallingford CT, 2016. https://gaussian.com/g16main/ 
15. R.G. Parr and R.G. Pearson, Absolute hardness: companion parameter to absolute electronegativity, J. Am. Chem. Soc., 1983, 105, no. 26, 7512-7516. doi: $\underline{10.1021 / \mathrm{ja00364a005}}$

16. N.A. Negm, M.F. Zaki, M.M. Said and S.M. Morsy, Inhibitory action of biodegradable modified vanillin on the corrosion of carbon steel in $1 \mathrm{M} \mathrm{HCl}$, Corros. Sci., 2011, 53, no. 12, 4233-4240. doi: 10.1016/j.corsci.2011.08.034

17. D.S. Shevtsov, O.A. Kozaderov, Kh.S. Shikhaliev, E.S. Komarova, A.A. Kruzhilin, A.Yu. Potapov, Ch. Prabhakar and I.D. Zartsyn, 3-Sulphinyl-5-Amino-1H-1,2,4Triazoles as Inhibitors of Copper Corrosion, Appl. Sci., 2019, 9, no. 22, 4882. doi: 10.3390/app9224882

18. E.S.M. Sherif and A.A. Almajid, Surface protection of copper in aerated 3.5\% sodium chloride solutions by 3-amino-5-mercapto-1,2,4-triazole as a copper corrosion inhibitor, J. Appl. Electrochem., 2010, 40, no. 8, 1555-1562. doi: 10.1007/s10800-010-0140-8

20. L. Yang, L. He, J. Zhang, S. An and L. Zhang, Exploring the copper (II) - aminotriazole complex-binding sites of human serum albumin, JBIC, J. Biol. Inorg. Chem., 2015, 20, no. 6, 1059-1068. doi: $10.1007 / \mathrm{s} 00775-015-1287-\mathrm{x}$

21. Yu.I. Kuznetsov, Kh.S. Shikhaliev, M.O. Agafonkina, N.P. Andreeva, A.M. Semiletov, A.A. Chirkunov, A.Yu. Potapov and V.E. Solov'ev, Formation of passivating layers by 1,2,4-triazole derivatives on copper in aqueous solutions, Russ. J. Phys. Chem. A, 2017, 91, 2458-2465. doi: 10.1134/S0036024417120147

22. M. Özcan, I. Dehri and M. Erbil, Organic sulphur-containing compounds as corrosion inhibitors for mild steel in acidic media: correlation between inhibition efficiency and chemical structure, Appl. Surf. Sci., 2004, 236, no. 1-4, 155-164. doi: $\underline{10.1016 / j . a p s u s c .2004 .04 .017}$ 